\title{
Polymorphisms of Heme Oxygenase-1 and Bilirubin UDP-Glucuronosyltransferase Genes are not Associated with Kawasaki Disease Susceptibility
}

\author{
Masayo Kanai, Saori Tanabe, Masahiko Okada, ${ }^{1}$ Hiroshi Suzuki, Takao \\ Niki, Michiniko Katsuura, ${ }^{2}$ Tomoharu Akiba ${ }^{3}$ and Kiyoshi Hayasaka ${ }^{1}$ \\ Department of Pediatrics, Yamagata University School of Medicine, Yamagata \\ 990-9585, \\ ${ }^{1}$ Department of Pediatrics, Yonezawa Municipal Hospital, Yamagata 992- \\ 8502 , \\ ${ }^{2}$ Department of Pediatrics, Yamagata Prefectural Kahoku Hospital, Yamagata \\ 999-3511, and \\ ${ }^{3}$ Department of Pediatrics, Saiseikan Yamagata Municipal Hospital, Yamagata \\ 999-8533
}

Kanai, M., Tanabe, S., Okada, M., Suzuki, H., Niki, T., Katsuura, M., Akiba, T. and Hayasaka, K. Polymorphisms of Heme Oxygenase-1 and Bilinubin UDPGlucuronosyltransferase Genes are not Associated with Kawasaki Disease Susceptibility. Tohoku J. Exp. Med., 2003, 200 (3), 155-159—_Kawasaki disease (KD) is a systemic vasculitis and occurs among Japanese children at a high incidence. Serum bilirubin and heme oxygenase-1 (HO-1) expression are known to play a significant role in the protection of vascular endothelial cells. Japanese have unique polymorphic distribution patterns of $(\mathrm{TA})_{7}$ or G71R of the bilirubin UDP-glucuronosyltransferase (B-UGT) gene and of $(\mathrm{GT})_{\mathrm{n}}$ repeats of the HO-1 gene. We investigated the relationship of $\mathrm{KD}$ susceptibility with these polymorphisms. There were no significant differences in the distribution of allele frequencies and genotypes of these polymorphisms between KD patients and controls. These polymorphisms are not associated with KD susceptibility. —— Kawasaki disease; heme oxygenase-1; bilirubin UDP-glucuronosyltransferase (C) 2003 Tohoku University Medical Press

Received June 9, 2003; revision accepted for publication July 24, 2003.

Address for reprints: Dr. Kiyoshi Hayasaka, Department of Pediatrics, Yamagata University School of Medicine, Yamagata 990-9585, Japan.

e-mail: hayasaka@med.id.yamagata-u.ac.jp 
Kawasaki disease (KD) is an acute systemic vasculitis that affects infant and children, and is frequently complicated with coronary aneurysm as a result of severe inflammation of the vessel walls. Although the first case report of $\mathrm{KD}$ was from Japan, KD has been reported worldwide (Kawasaki et al. 1974). An infectious agent is suspected for its pathogenesis, however, the cause of $\mathrm{KD}$ is still unknown. On the other hand, there is a racial difference in the incidence of $\mathrm{KD}$ and it occurs among Japanese children at a high incidence (Yanagawa et al. 1995). In addition, familial cases have been also reported, suggesting that genetic factors are associated with KD susceptibility. Considering the pathogenesis of $\mathrm{KD}$ as vasculitis, we noted two factors involved in bilirubin metabolism, which may have a significant role in the protection of vascular endothelial cells.

Bilirubin has the potential to serve as an antioxidant and a radical scavenger. A mild increase in serum bilirubin level provides protection against the risk of coronary artery disease (CAD) (Mayer 2000). Bilirubin is metabolized by bilirubin UDP-glucuronosyltransferase (BUGT), the gene of which has common polymorphic mutations $(\mathrm{TA})_{7}$ in the promoter and G71R in the coding region. These polymorphisms decrease the expression level or catalytic activity of B-UGT leading to mild hyperbilirubinemia. In 1998, we reported that the Japanese population has a rare $(\mathrm{TA})_{7}$ mutation and a frequent G71R mutation, which are significantly different from Caucasians (Akaba et al. 1998).

Heme oxygenase (HO-1), the rate-limiting enzyme of bilirubin production, is a stressresponse protein that also plays an important role in cell defense mechanisms against oxidative injury (Okinaga et al. 1996; Yamada et al. 1999). HO-1 has polymorphic $(G T)_{n}$ repeats in the promoter, which regulate the expression of HO-1 (Kimpara et al. 1997).
Yamada et al. (2000) reported that a longer $(\mathrm{GT})_{\mathrm{n}}$ repeat decreased the HO-1 expression level and its allele frequency was significantly higher in the smokers with chronic pulmonary emphysema than in smokers without chronic pulmonary emphysema. It was also reported that a longer $(\mathrm{GT})_{\mathrm{n}}$ repeat was a risk factor for developing CAD (Kaneda et al. 2002). Recently, we have noted that Japanese have a different distribution pattern in these polymorphic $(\mathrm{GT})_{\mathrm{n}}$ repeats from Caucasians (Kanai et al. 2003).

In this study, we investigated the relationship between $\mathrm{KD}$ and the genetic factors involved in bilirubin metabolism, which may have a significant role in the protection of vascular endothelial cells and have unique polymorphic distribution patterns among the Japanese population.

\section{MATERIALS AND METHODS}

With the informed consent of the parents, 61 patients with $\mathrm{KD}$ or a history of $\mathrm{KD}$ were enrolled in this study and genomic DNA samples were extracted from their peripheral blood. $\mathrm{KD}$ was diagnosed based on the conventional criteria, that is requiring the presence of at least five of six characteristic clinical features. The mean age of the patients at the diagnosis was $24.3 \pm 19.1$ (range, 2-66) months and the ratio of boys to girls was $36: 25$. Aneurysm or dilatation of the coronary arteries developed in seven patients during the acute phase of the disease. The results were compared with those of 122 randomly sampled healthy Japanese as the control. This study was approved by the Institutional Review Board of the Yamagata University School of Medicine. (TA $)_{7}$ and G71R mutations of the B-UGT gene were analyzed as described previously (Akaba et al. 1998). The number of $(\mathrm{GT})_{\mathrm{n}}$ repeats in the promoter region of the HO-1 gene was determined by fragment analysis with a Genescan ${ }^{\circledR}$ application using an ABI PRISM ${ }^{\circledR}$ Genetic Analyzer 310 (PE Applied 
TABLE 1. Distributions of HO-1 and B-UGT polymorphisms

\begin{tabular}{|c|c|c|}
\hline & $\begin{array}{l}\text { KD patients } \\
\text { (No. [\%]) }\end{array}$ & $\begin{array}{c}\text { Controls } \\
(\text { No. }[\%])\end{array}$ \\
\hline \multicolumn{3}{|l|}{ HO-1 gene } \\
\hline \multicolumn{3}{|l|}{$(\mathrm{GT})_{\mathrm{n}}$ repeats } \\
\hline \multicolumn{3}{|l|}{ Allele frequency* } \\
\hline S & $60(49.2)$ & $111(45.5)$ \\
\hline M & $48(39.3)$ & $88(36.1)$ \\
\hline $\mathrm{L}$ & $14(11.5)$ & $45(18.4)$ \\
\hline \multicolumn{3}{|l|}{ Genotypes** } \\
\hline SS & $18(29.5)$ & $26(21.3)$ \\
\hline SM & $17(27.9)$ & $45(36.9)$ \\
\hline SL & $7(11.5)$ & $14(11.5)$ \\
\hline MM & $12(19.7)$ & $12(9.8)$ \\
\hline ML & $7(11.5)$ & $19(15.6)$ \\
\hline LL & $0 \quad(0)$ & $6 \quad(4.9)$ \\
\hline \multicolumn{3}{|l|}{$B$-UGT gene } \\
\hline \multicolumn{3}{|l|}{ G71R mutation } \\
\hline Allele frequency & $31(25.4)$ & $43(17.6)$ \\
\hline \multicolumn{3}{|l|}{ Genotypes } \\
\hline G71/G71 & $34(55.7)$ & $84(68.9)$ \\
\hline G71/R71 & $23(37.7)$ & $33(27.0)$ \\
\hline $\mathrm{R} 71 / \mathrm{R} 71$ & $4 \quad(6.6)$ & $5 \quad(4.1)$ \\
\hline \multicolumn{3}{|l|}{$(\mathrm{TA})_{7}$ mutation } \\
\hline Allele frequency & $8 \quad(6.6)$ & $20 \quad(8.2)$ \\
\hline \multicolumn{3}{|l|}{ Genotypes $\dagger$} \\
\hline$(\mathrm{TA})_{6} /(\mathrm{TA})_{6}$ & $53(86.9)$ & $102(83.6)$ \\
\hline$(\mathrm{TA})_{6} /(\mathrm{TA})_{7}$ & $8(13.1)$ & $20(16.4)$ \\
\hline$(\mathrm{TA})_{7} /(\mathrm{TA})_{7}$ & $0 \quad(0)$ & $0 \quad(0)$ \\
\hline
\end{tabular}

*Alleles classified by the number of $(\mathrm{GT})_{\mathrm{n}}$ repeats in the promoter; $\mathrm{S}$, alleles with 26 or less repeats; M, from 27 to 32; L, 33 or greater.

**Genotypes based on three allele classes.

$\dagger(\mathrm{TA})_{6} /(\mathrm{TA})_{6}$ was homozygote for wild type; $(\mathrm{TA})_{6} /(\mathrm{TA})_{7}$, heterozygote for wild type and mutated $(\mathrm{TA})_{7}$ alleles; $(\mathrm{TA})_{7} /(\mathrm{TA})_{7}$, homozygote for mutated $(\mathrm{TA})_{7}$ allele. KD, Kawasaki disease.

Biosystems, Foster City, CA, USA)(Yamada et al. 2000; Kanai et al. 2003). The $\chi^{2}$-test was used in the comparison between the two groups.

\section{RESULTS}

As shown in Table 1, there were no significant differences in the allele frequencies and genotypes of $(\mathrm{TA})_{7}$ and G71R mutation of the B-UGT gene between the KD patients and healthy controls.
We compared the numbers of $(\mathrm{GT})_{\mathrm{n}}$ repeats in the promoter region of the HO-1 gene after dividing the repeats into three classes, S, M and $\mathrm{L}$, depending on the size of the repeats. There were also no significant differences in the distribution patterns of allele frequencies and genotypes of $(\mathrm{GT})_{\mathrm{n}}$ repeats between the $\mathrm{KD}$ patients and healthy controls. 


\section{DISCUSSION}

Racial difference in its incidence and a greater risk of developing $\mathrm{KD}$ in the siblings suggest an influence of genetic factors on disease susceptibility. Ouchi et al. (2003) reported an association between KD susceptibility and a polymorphism of the SLC11A1 gene, which regulates the cascade of gene-inductive events that follow the interaction of macrophages with bacterial lipopolysacchride and/or natural killer cell-or T cell-derived interferon- $\gamma$. Considering the pathogenesis of $\mathrm{KD}$ as systemic vasculitis, we noted a protective effect of serum bilirubin and HO-1 expression on oxidative and atherogenic vascular injuries (Mayer 2000; Kaneda et al. 2002), and unique distribution patterns of polymorphisms of the B-UGT and HO-1 genes in the Japanese population (Akaba et al. 1998; Kanai et al. 2003). However, we could not find a significant differences in the distribution patterns of allele frequencies and genotypes of two polymorphic (TA) $)_{7}$ and G71R mutation of the B-UGT gene. We also could not find a significant difference in the distribution pattern of $(\mathrm{GT})_{\mathrm{n}}$ repeats of the HO-1 gene between the $\mathrm{KD}$ patients and healthy controls. These polymorphic mutations of the genes involved in heme metabolism are not associated with KD susceptibility. Regarding the association of $\mathrm{KD}$ with the development of coronary aneurysm, the number of patients was too small for statistical analysis and a larger population should be studied.

In conclusion, polymorphisms in the promoter or coding region of the B-UGT gene and in the promoter region of the HO-1 gene are not associated with the susceptibility to $\mathrm{KD}$.

\section{Acknowledgements}

We would like to thank Dr. Y. Yoshimura for referring his patients to us and Ms. M. Watanabe for help in preparing the manuscript.

\section{References}

Akaba, K., Kimura, T., Sasaki, A., Tanabe, S., Ikegami, T., Hashimoto, M., Umeda, H., Yoshida, H., Umetsu, K., Chiba, H., Yuasa, I. \& Hayasaka, K. (1998) Neonatal hyperbilirubinemia and mutation of the bilirubin uridine diphosphate-glucuronosyltransferase gene: a common missense mutation among Japanese, Koreans and Chinese. Biochem. Mol. Biol. Int., 46, 21-26.

Kanai, M., Akaba, K., Sasaki, A., Sato, M., Harano, T., Shibahara, S., Kurachi, H., Yoshida, T. \& Hayasaka, K. (2003) Neonatal hyperbilirubinemia in Japanese: analysis of the heme oxygenase-1 gene and fetal hemoglobin composition in cord blood. Pediatr. Res., 54, 1-8.

Kaneda, H., Ohno, M., Taguchi, J., Togo, M., Hashimoto, H., Ogasawara, K., Aizawa, T., Ishizaka, N. \& Nagai, R. (2002) Heme oxygenase-1 gene promoter polymorphism is associated with coronary artery disease in Japanese patients with coronary risk factors. Arterioscler. Thromb. Vasc. Biol., 22, 16801685.

Kawasaki, T., Kosaki, F., Okawa, S., Shigematsu, I. \& Yanagawa, H. (1974) A new infantile acute febrile mucocutaneous lymph node syndrome (MLNS) prevailing in Japan. Pediatrics, 54, 271-276.

Kimpara, T., Takeda, A., Watanabe, K., Itoyama, Y., Ikawa, S., Watanabe, M., Arai, H., Sasaki, H., Higuchi, S., Okita, N., Takase, S., Saito, H., Takahashi, K. \& Shibahara, S. (1997) Microsatellite polymorphism in the human heme oxygenase-1 gene promoter and its application in association studies with Alzheimer and Parkinson disease. Hum. Genet., 100, 145 $-147$.

Mayer, M. (2000) Association of serum bilirubin concentration with risk of coronary artery disease. Clin. Chem., 46, 1723-1727.

Okinaga, S., Takahashi, K., Takeda, K., Yoshizawa, M., Fujita, H., Sasaki, H. \& Shibahara, S. (1996) Regulation of human heme oxygenase-1 gene expression under thermal stress. Blood, 87, 5074-5084.

Ouchi, K., Suzuki, Y., Shirakawa, T. \& Kishi, F. (2003) Polymorphism of SLC11A1 (formerly NRAMP1) gene confers susceptibility to Kawasaki disease. J. Infect. Dis., 187, 326329. 
Yamada, N., Yamaya, M., Okinaga, S., Lie, R., Suzuki, T., Nakayama, K., Takeda, A., Yamaguchi, T., Itoyama, Y., Sekizawa, K. \& Sasaki, H. (1999) Protective effects of heme oxygenase-1 against oxidant-induced injury in the cultured human tracheal epithelium. Am. J. Respir. Cell Mol. Biol., 21, 428-435.

Yamada, N., Yamaya, M., Okinaga, S., Nakayama, K., Sekizawa, K., Shibahara, S. \& Sasaki, H.
(2000) Microsatellite polymorphism in the heme oxygenase- 1 gene promoter is associated with susceptibility to emphysema. Am.J. Hum. Genet., 66, 187-195.

Yanagawa, H., Yashiro, M., Nakamura, Y., Kawasaki, T. \& Kato, H. (1995) Results of 12 nationwide epidemiological incidence surveys of Kawasaki disease in Japan. Arch. Pediatr. Adolesc. Med., 149, 779-783. 